\title{
A temporary immersion system improves regeneration of in vitro irradiated recalcitrant rice embryogenic calli.
}

\author{
Alejandro Hernández-Soto1,2*, Jason Pérez², Rebeca Fait-Zuñiga², Randall Rojas-Vásquez ${ }^{3}$, Andrés Gatica-Arias ${ }^{3}$, \\ and Ana Abdelnour-Esquivel ${ }^{2}$ \\ 1 Doctorado en Ciencia Naturales para el Desarrollo (DOCINADE), Instituto Tecnológico de Costa Rica, Uni- \\ versidad Nacional, Universidad Estatal a Distancia, Cartago P.O. Box 159-7050, Costa Rica \\ 2 Costa Rica Institute of Technology, Biology School, Biotechnology Research Center. Costa Rica, PO Box 159- \\ 7050 Cartago, Costa Rica \\ 3 Costa Rica University of Costa Rica, School of Biology, Plant Biotechnology Laboratory, P.O. Box 2060, San \\ José, Costa Rica \\ * Correspondence: alhernandez@tec.ac.cr
}

\begin{abstract}
The development of gamma ray-mutated rice lines is a solution for introducing variability in rice varieties already being used by farmers. In vitro gamma ray (60Co) mutagenesis reduces chimeras and allows a faster selection of desired traits but requires optimization of the laboratory procedure. The objectives of the present work were the in vitro establishment of recalcitrant rice embryogenic calli, the determination of their sensitivity to gamma radiation (60Co), sequencing of MATK and Rubisco genes for identification purposes, and optimization of the generation procedure. The radiosensitivity of the embryogenic calli showed an LD50 at $110 \mathrm{~Gy}$, while the $20 \%$ lethal dose was 64 Gy. All sequenced genes matched perfectly with previously reported MATK and Rubisco O. sativa genes, with a clear SNP that identified the local variety as being related to one in the Southeast Asia region. Callus induction improved in MS medium containing $2 \mathrm{mg} / \mathrm{L}$ 2,4-D, and regeneration was achieved with MS medium with $3 \mathrm{mg} / \mathrm{L}$ BAP and $0.5 \mathrm{mg} / \mathrm{L}$ NAA. The optimized radiation condition was $60 \mathrm{~Gy}$, with $83 \%$ regeneration in a semisolid medium, allowing a balance between mutation and regeneration. When the radiation increased to $80 \mathrm{~Gy}$, the regeneration rate fell to $29 \%$. An immersion system (RITA®) of either 60 or 120 seconds every 8 hours allowed systematic and homogeneous total regeneration of the recalcitrant line, in contrast with the semisolid medium that resulted in positive but irregular regeneration. Other well-known recalcitrant cultivars, CR1821 and CR1113, also had improved regeneration in the immersion system, demonstrating their potential use as recalcitrant materials. To our knowledge, this is the first report on using an immersion system to allow regeneration of gamma-ray mutants from recalcitrant rice materials.
\end{abstract}

Keywords: Embryogenesis; Cobalt-60 radiation-induced mutagenesis; Temporary immersion systems (TIS).

\section{Introduction}

Rice is an important cereal that provides $20 \%$ of the world's energy, particularly in Asia, Africa, and Latin America. The Oryza genus consists of 22 species, but only two are commonly planted: $O$. sativa and O. glaberrima ${ }^{1-5}$. Of those, farmers prefer only a few cultivars, depending on the country. The limited variability of commercial materials can become an obstacle in increasing productivity given emerging conditions such as heat, salt stress, soil acidification, plague sensitivity, and weeds. Introducing variability with crossbreeding is slow and can result in the introduction of undesired traits. Radiation methods to generate variability in seeds are common techniques used since 1928 on vegetables, while other methods exist, such as the use of ethyl methanesulfonate (EMS) and new breeding techniques to introduce specific genetically engineered mutations ${ }^{6-11}$. 
Plant tissue culture represents an opportunity to overcome time limitations, land requirements, and selection of the desired variability that results when using gamma ray mutagenesis in seeds. Once irradiated, the seeds must be planted several times (M0 to M4) to avoid chimeras and heterogenicity until exposed to stress selection conditions, as has been done in the past6,8. In contrast, rice tissue culture can produce a primitive cell aggregate or callus with embryogenic potential and consequently mutate and regenerate from one or a few cells with stressor selection from the beginning 12,13 .

The latter is possible because plant cells are totipotent, which means that whole plants can develop from the single cells ${ }^{14}$. Mutation in the embryogenic callus using gamma radiation was previously developed in our lab for the cultivar CR5272 for salt tolerance; however, farmers no longer use this cultivar and instead use modern materials that are more recalcitrant to tissue culture ${ }^{13}$. The establishment of embryogenic rice calli is influenced by the germplasm of origin and the 2,4-D concentration ${ }^{14,15}$. Embryogenic cells result when exposed to Murashige and Skoog (1962) medium supplemented with 2 to $2.5 \mathrm{mg} / 12$,4-D, resulting in pro-embryos and somatic embryos ${ }^{16-18}$. Costa Rican cultivars such as CR-201, CR-1707, CR-1821, CR-8334, and CR-8341 have unpredictable and variable behavior, while CR-1113 and CR-5272 have predictable induction and regeneration in $2.5 \mathrm{mg} / \mathrm{L} 2,4-\mathrm{D}^{19}$.

Here, we faced the challenge of identifying our material with the commonly used molecular markers MATK and Rubisco, improving our plant tissue culture methods, and determining the radiosensitivity of embryogenic calli and further regeneration. We present a simple method to induce mutations using gamma rays in embryogenic calli of a recalcitrant cultivar, with an alternative immersion method that allowed our material to fully generate homogeneous and predictable in vitro plants after irradiation.

\section{Results}

The MATK MZ558335 and Rubisco MZ558334 sequences showed perfect matches with the already published NCBI $O$. sativa indica accessions and demonstrated the identity of the material as expected. We detected three synonymous mutations in the Rubisco sequence that are important for the characterization of the variety. Specifically, one synonymous SNP on the sixth glutamic acid triplet (GAA/GAG) gives clues of a putative origin of the germplasm ancestors from the Southeast Asia region because of its unique presence and matches with three cultivars of the region: the Pakistan cultivar NARC 17958 (GenBank KP827660.1), the Indonesia cultivar Pandak Kembang (GenBank MZ198248) and the Vietnam cultivar "Lua Khau Ky" isolate GBVN15800 (GenBank KR073275.1). We also detected two synonymous biallelic mutations at glycine 82 and 150 codifying triplets (GGC/GGA; GGT/GGC), which helped characterize and further identify the material. None of the mutations suggested biological importance since the open reading frame remains unaltered.

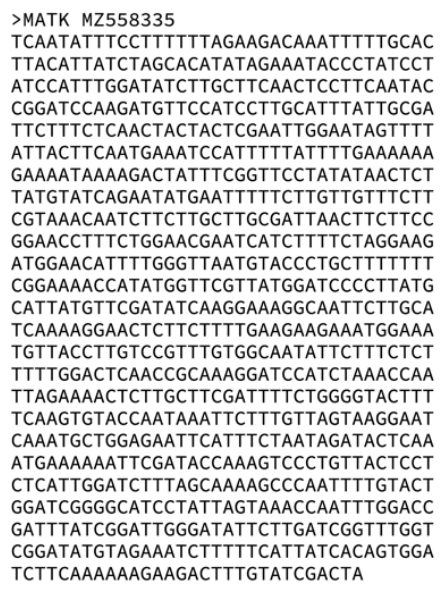

>Rubisco MZ558334 TTTTTTGCAGATAATCCCAATTTTGGTTTAATAGTACAT CCCAATAAAGGACGACCGTATTTGTTCAACTATTACAT CCCAATAAAGGACGACCGTATTTGTTCAACTTATCCCTT TCAACTTGGATACCATGAGGCGGACCTTGGAAATTTT GAATAAGTAGGGGGAATTCGCAGATCCTCCAGACGTAGA GCGCGTAGGGCTTTGAAACCAAATACGTTACCCACAATG GAAGTAAACATGTTAGTAACAGAACCCTCTTCAAATAGG TCTAATGGATAAGCTACATAAGCGATATATTGATTATCC TCCCCAACAACGGGCTCGATGTGATAGCATCGGCCTTTG GTCCATGTACCAGTAGAAGATTCGGCAGCTACTGCAGCC CCTGCTTCTTCGGGCGGAACCCCCGGCTGAGGAGTTACT CGGAATGCTGCCAAGATATCAGTGTCCTTGGTTTCGTAC TCCGGGGTGTAGTAAGTCAATTTATAATCCTTAACACCA GCTTTAAATCCAACACTTGCTTTAGTCTCTGTTTGTGGG G
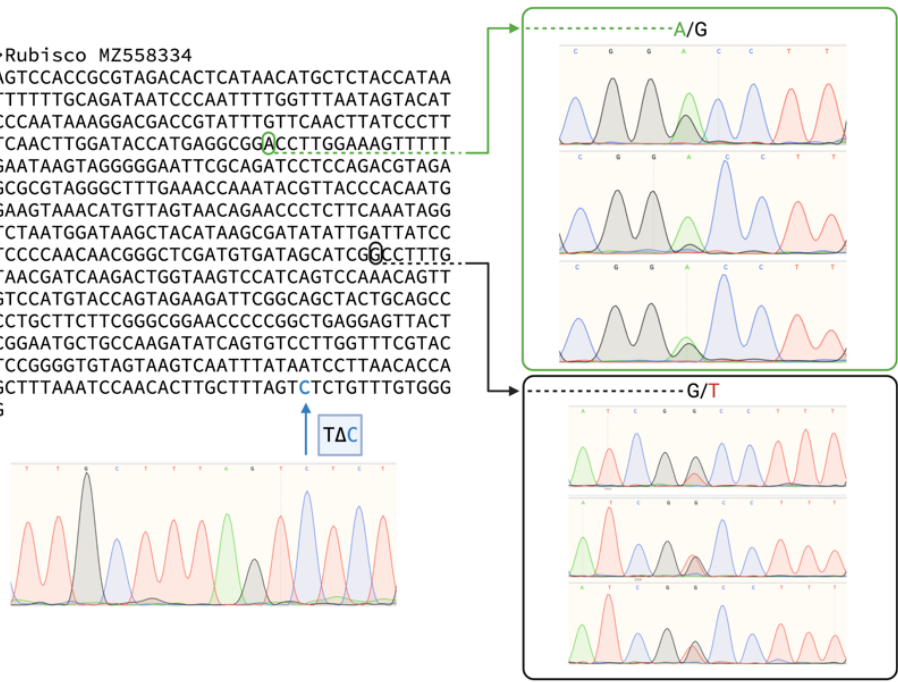
Figure 1. DNA markers used to identify the MATK and Rubisco genes in the local rice variety. Note in green the synonymous SNP $(\mathrm{C} / \mathrm{T})$ and the biallelic synonymous mutations $\mathrm{A} / \mathrm{G}$ and $\mathrm{G} / \mathrm{T}$ (circled). None of the mutations had biological importance but helped in the genetic characterization of the cultivar.

Rice tissue culture

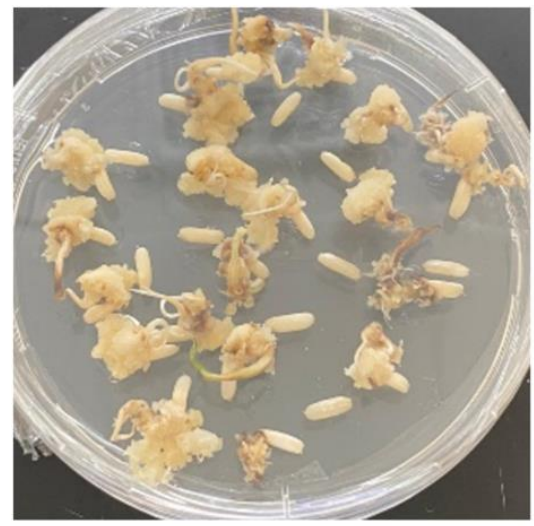

(A.)

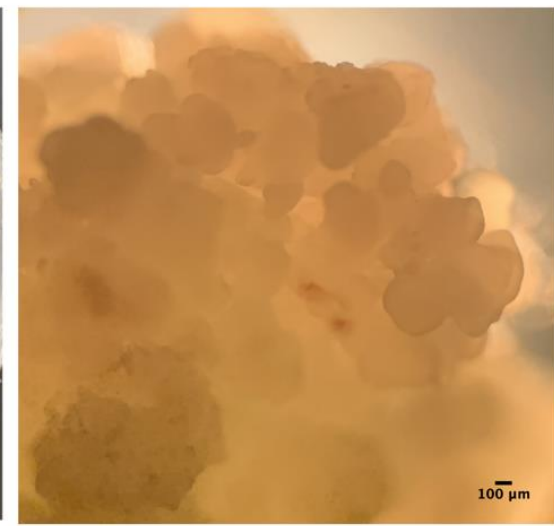

(B.)

Figure 2. Calli induction on MS medium with 2 mg/L 2,4-D after 30 days. (A) The induction in Petri dishes and (B) the compact and friable calli as observed under the stereoscope.

Table 1. Rice callus induction and oxidation rate from different induction treatments

\begin{tabular}{ccc}
\hline Treatment & Embryogenic calli (\%) & Oxidation rate (\%) \\
\hline 1 mg BAP + 1 mg de 2,4-D & $12.77 \mathrm{~d}$ & $0.66 \mathrm{c}$ \\
$1 \mathrm{mg} \mathrm{BAP}+2 \mathrm{mg}$ de 2,4-D & $16.77 \mathrm{c}$ & $0.21 \mathrm{c}$ \\
$2 \mathrm{mg} 2,4-\mathrm{D}+0,25 \mathrm{mg}$ de TDZ & $23.00 \mathrm{~b}$ & $0.66 \mathrm{c}$ \\
$2 \mathrm{mg} 2,4-\mathrm{D}$ & $71.44 \mathrm{a}$ & $3.55 \mathrm{a}$ \\
$2,5 \mathrm{mg} 2,4-\mathrm{D}$ & $21.44 \mathrm{~b}$ & $2.00 \mathrm{~b}$ \\
$1 \mathrm{mg} \mathrm{BAP}+1 \mathrm{mg} 2,4-\mathrm{D}$ & $12.77 \mathrm{~d}$ & $0.66 \mathrm{c}$ \\
\hline
\end{tabular}

${ }^{1}$ All treatments had 30 replicates $(n=30)$. Letters represent a significant differences $(p \leq 0.05)$.

The best callus induction was achieved with $2 \mathrm{mg} / \mathrm{L} 2,4-\mathrm{D}$ alone. The callus induction step with a $2 \mathrm{mg} / \mathrm{L}$ 2,4-D concentration was initially not expected because of previous local cultivar reports. Local cultivars CR5272 and CR1113 had a positive response at $2.5 \mathrm{mg} / \mathrm{L}$ 2.4 D but a low performance at $2 \mathrm{mg} / \mathrm{L} \mathrm{2,4-D,} \mathrm{while} \mathrm{CR-201,} \mathrm{CR-1707,} \mathrm{CR-1821,} \mathrm{CR-8334,}$ and CR-8341 had recalcitrant and unpredictable in vitro behaviors ${ }^{16,19}$. Similarly, better callus induction occurred with higher concentrations of 2,4-D (from $2.5 \mathrm{mg}$ to $3 \mathrm{mg} / \mathrm{L}$ ) with other cultivars, such as MR220, GNY-53, and JP-5 22,23. In our case, the positive induction at $2 \mathrm{mg} / \mathrm{L}$ 2,4-D contrasted with higher oxidation and represented a challenge for the next steps of regeneration and our final irradiation goal, which also triggers oxidation.

Table 2. Rice callus regeneration, sprouting and oxidation rate of different treatments

\begin{tabular}{clccc}
\hline $\begin{array}{c}\text { Induction } \\
\text { Treatment }\end{array}$ & \multicolumn{1}{c}{ Regeneration Treatment } & $\begin{array}{c}\text { Regenera- } \\
\text { tion } \mathbf{( \% )}\end{array}$ & $\begin{array}{c}\text { Sprouting } \\
\mathbf{( \% )}\end{array}$ & $\begin{array}{c}\text { Oxidation } \\
\mathbf{( \% )}\end{array}$ \\
\hline $2 \mathrm{mg} 2,4-\mathrm{D}$ & $0.5 \mathrm{mg}$ ANA + 3 mg BAP & $69.04 \mathrm{a}$ & $7.14 \mathrm{ab}$ & $9.52 \mathrm{~d}$ \\
& 0.5 mg ANA + 0.5 mg TDZ & $38.09 \mathrm{c}$ & $2.38 \mathrm{~b}$ & $61.90 \mathrm{a}$ \\
& 0.5 mg ANA + 0.5 mg Kinetina & $47.61 \mathrm{~b}$ & $9.52 \mathrm{a}$ & $23.80 \mathrm{c}$ \\
& $0.5 \mathrm{mg}$ ANA + 0.5 mg BAP & $28.57 \mathrm{~d}$ & $2.38 \mathrm{~b}$ & $54.76 \mathrm{~b}$ \\
\hline 1 mg BAP + 2 & 0.5 mg ANA + 3 mg BAP & & & \\
\hline mg 2,4-D & $0.5 \mathrm{mg}$ ANA + 0,25 mg TDZ & $28.29 \mathrm{~b}$ & $0 \mathrm{a}$ & $58.43 \mathrm{~b}$ \\
& $0.5 \mathrm{mg}$ ANA + 0.5 mg Kinetina & $58.82 \mathrm{a}$ & $0 \mathrm{a}$ & $100 \mathrm{a}$ \\
& & $9.22 \mathrm{c}$ & $0 \mathrm{a}$ & $56.81 \mathrm{~b}$
\end{tabular}




\begin{tabular}{|c|c|c|c|c|}
\hline & $0.5 \mathrm{mg}$ ANA + $0.5 \mathrm{mg}$ BAP & $12.82 \mathrm{c}$ & $0 \mathrm{a}$ & $44.26 \mathrm{c}$ \\
\hline $\begin{array}{c}1 \mathrm{mg} \mathrm{BAP}+1 \\
\mathrm{mg} 2,4-\mathrm{D}\end{array}$ & $\begin{array}{l}0.5 \mathrm{mg} \text { de ANA + } 3 \mathrm{mg} \text { BAP } \\
0.5 \mathrm{mg} \text { de ANA + } 0.5 \mathrm{mg} \text { TDZ } \\
0.5 \mathrm{mg} \text { de ANA + } 0.5 \mathrm{mg} \text { Kinetin } \\
0.5 \mathrm{mg} \text { de ANA + } 0.5 \mathrm{mg} \text { BAP } \\
0.5 \mathrm{mg} \text { de ANA + } 3 \mathrm{mg} \text { BAP }\end{array}$ & $\begin{array}{c}58.45 \mathrm{ab} \\
61.75 \mathrm{a} \\
56.31 \mathrm{ab} \\
49.88 \mathrm{~b} \\
58.45 \mathrm{ab}\end{array}$ & $\begin{array}{c}16.38 \mathrm{a} \\
10.71 \mathrm{ab} \\
15.92 \mathrm{a} \\
4.16 \mathrm{~b} \\
16.38 \mathrm{a}\end{array}$ & $\begin{array}{c}18.69 \mathrm{bc} \\
27.93 \mathrm{a} \\
20.01 \mathrm{ab} \\
11.66 \mathrm{c} \\
18.69 \mathrm{bc}\end{array}$ \\
\hline $2,5 \mathrm{mg} 2,4-\mathrm{D}$ & $\begin{array}{l}0.5 \text { mg ANA + } 3 \text { mg BAP } \\
0.5 \text { mg ANA + 0.5 mg TDZ } \\
0.5 \text { mg ANA + 0.5 mg Kinetin } \\
0.5 \text { mg ANA + 0.5 mg BAP }\end{array}$ & $\begin{array}{c}34.64 \mathrm{~b} \\
51.41 \mathrm{a} \\
43.62 \mathrm{ab} \\
18.00 \mathrm{c}\end{array}$ & $\begin{array}{c}0 \mathrm{~b} \\
9.61 \mathrm{a} \\
0 \mathrm{~b} \\
0 \mathrm{~b}\end{array}$ & $\begin{array}{c}9.20 \mathrm{c} \\
22.96 \mathrm{a} \\
15.73 \mathrm{~b} \\
15.19 \mathrm{~b}\end{array}$ \\
\hline $\begin{array}{l}2 \mathrm{mg} 2,4-\mathrm{D}+ \\
0,25 \mathrm{mg} \text { TDZ }\end{array}$ & $\begin{array}{l}0.5 \mathrm{mg} \text { ANA + } 3 \mathrm{mg} \text { BAP } \\
0.5 \mathrm{mg} \text { ANA + } 0.5 \mathrm{mg} \text { TDZ } \\
0.5 \mathrm{mg} \text { ANA + 0.5 mg Kinetin } \\
0.5 \mathrm{mg} \text { ANA + 0.5 mg BAP }\end{array}$ & $\begin{array}{l}77.27 \mathrm{a} \\
50.25 \mathrm{~b} \\
73.86 \mathrm{a} \\
44.29 \mathrm{~b}\end{array}$ & $\begin{array}{c}2.27 \mathrm{a} \\
0 \mathrm{a} \\
3.40 \mathrm{a} \\
0 \mathrm{a}\end{array}$ & $\begin{array}{l}96.59 \mathrm{a} \\
86.36 \mathrm{~b} \\
82.95 \mathrm{~b} \\
72.81 \mathrm{c}\end{array}$ \\
\hline
\end{tabular}

${ }^{1}$ All treatments had 6 replicates $(n=6)$. Letters represent significant differences $(p \leq 0.05)$.

The best regeneration rate of approximately $70 \%$ resulted from $0.5 \mathrm{mg}$ of NAA+ $3 \mathrm{mg}$ of 6 -BAP, with sprouting of $7.14 \%$ and oxidation of only $9.52 \%$ (Table 2 ). Other regeneration medium recipes also resulted in regeneration but with higher oxidation and were consequently useless for our next step, the gamma radiation mutagenesis.

The lethal dose of the embryogenic calli was $110 \mathrm{~Gy}$, while the $20 \%$ lethal dose was $64 \mathrm{~Gy}$, resulting in a 0 to 120 gray gradient exposure, with 200 calli per exposure (Table 3 ).

Table 3. Probit gamma ray lethal dose calculation on the rice embryogenic calli ${ }^{1}$

\begin{tabular}{llll}
\hline $\begin{array}{l}\text { Lethal gamma rays } \\
\text { dose model }\end{array}$ & Dose (Gy) & Lower limit (Gy) & Upper limit (Gy) \\
\hline LD10 & 41,145 & 34,552 & 46,708 \\
LD20 & 64,799 & 60,083 & 69,20 \\
LD25 & 73.785 & 69,388 & 78,139 \\
LD30 & 81,855 & 77,507 & 86,403 \\
LD40 & 96,429 & 91,649 & 101,85 \\
LD50 & 110,050 & 104,435 & 116,720 \\
\hline
\end{tabular}

${ }^{1}$ All treatments had 10 replicates with 20 calli each $(\mathrm{n}=20), p \leq 0.05$. Data were compiled at 30 days post-radiation.

The best radiation/regeneration ratio was achieved at $60 \mathrm{~Gy}$ with $83 \%$ regeneration, allowing a balance between gamma radiation at lethal dose 20 and regeneration (Table 4). The increased regeneration achieved with $40 \mathrm{~Gy}$ and $60 \mathrm{~Gy}$ versus the control is a hormetic behavior previously reported in our $l a b^{13}$.

Table 4. Radiation dose influence on regeneration, sprouting and oxidation rates ${ }^{1}$

\begin{tabular}{llll}
\hline Radiation dose & Regeneration & Sprouting & Oxidation \\
\hline $80 \mathrm{~Gy}$ & $29.76 \mathrm{~d}$ & $0 \mathrm{c}$ & $15.47 \mathrm{a}$ \\
$60 \mathrm{~Gy}$ & $83.85 \mathrm{a}$ & $0 \mathrm{c}$ & $3.57 \mathrm{c}$ \\
$40 \mathrm{~Gy}$ & $75.00 \mathrm{~b}$ & $3.57 \mathrm{~b}$ & $7.14 \mathrm{bc}$ \\
$0 \mathrm{~Gy}$ & $69.04 \mathrm{c}$ & $7.14 \mathrm{a}$ & $9.52 \mathrm{~b}$ \\
\hline
\end{tabular}

${ }^{1}$ All treatments had 12 replicates $(n=20), p \leq 0.05$. Data were compiled at 15 days post-radiation. 


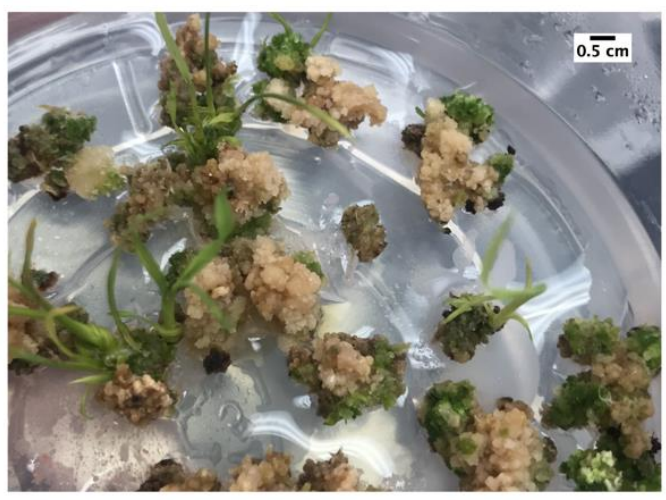

(A.)

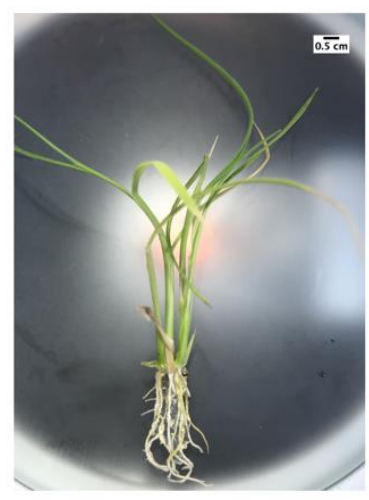

(B.)

Figure 3. Regeneration of 60 Gy irradiated calli after (A) 45 days and (B) 60 days.

Gamma-irradiated calli regenerated plants after 45 days in induction medium and fully in vitro plants at 60 days post-irradiation.

Table 6. Immersion regeneration, sprouting and oxidation rates ${ }^{1}$

\begin{tabular}{llll}
\hline Immersion time per 8 hrs & Regeneration & Sprouting & Oxidation \\
\hline 60 seconds & $100.00 \mathrm{a}$ & $25.00 \mathrm{a}$ & $60.00 \mathrm{a}$ \\
120 seconds & $97.56 \mathrm{a}$ & $31.71 \mathrm{a}$ & $97.56 \mathrm{a}$ \\
\hline
\end{tabular}

${ }^{1}$ All treatments had 12 replicates $(n=20), p \leq 0.05$. Data were compiled at 15 days post-radiation.

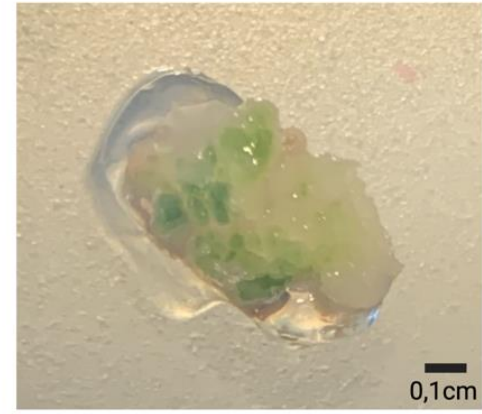

(A.)

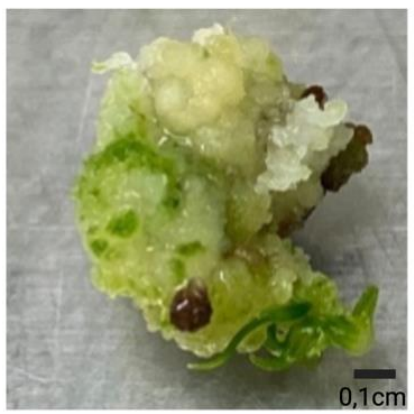

(B.)

Figure 4. Regeneration in MS medium with $0.5 \mathrm{mg}$ ANA $+3 \mathrm{mg}$ BAP of an induced callus with 2 $\mathrm{mg} / \mathrm{L}$ of 2,4-D after 15 days of induction. Regeneration in (A) semisolid medium and (B) RITA®.

The potential of a temporary immersion system for regenerating difficult materials was also validated for the well-known recalcitrant cultivars CR1821 and CR1113 (Table 7, Fig. 5).

Table 7. Immersion regeneration, sprouting and oxidation rates for the controls ${ }^{1}$

\begin{tabular}{lcll}
\hline Cultivar & Immersion time per 12 hrs & Regeneration & Oxidation \\
\hline CR5272 & 60 seconds & $100.00 \mathrm{a}$ & 60.00 \\
CR5272 & 120 seconds & $100.00 \mathrm{a}$ & 60.00 \\
CR1821 & 60 seconds & $55.00 \mathrm{~b}$ & 50.00 \\
CR1821 & 120 seconds & $60.00 \mathrm{~b}$ & 50.00 \\
CR1113 & 60 seconds & $45.00 \mathrm{~b}$ & 60.00 \\
CR1113 & 120 seconds & $50.00 \mathrm{~b}$ & 60.00 \\
\hline
\end{tabular}

${ }^{1}$ All treatments had 12 replicates $(n=20), p \leq 0.05$. Data were compiled at 15 days post-radiation. 

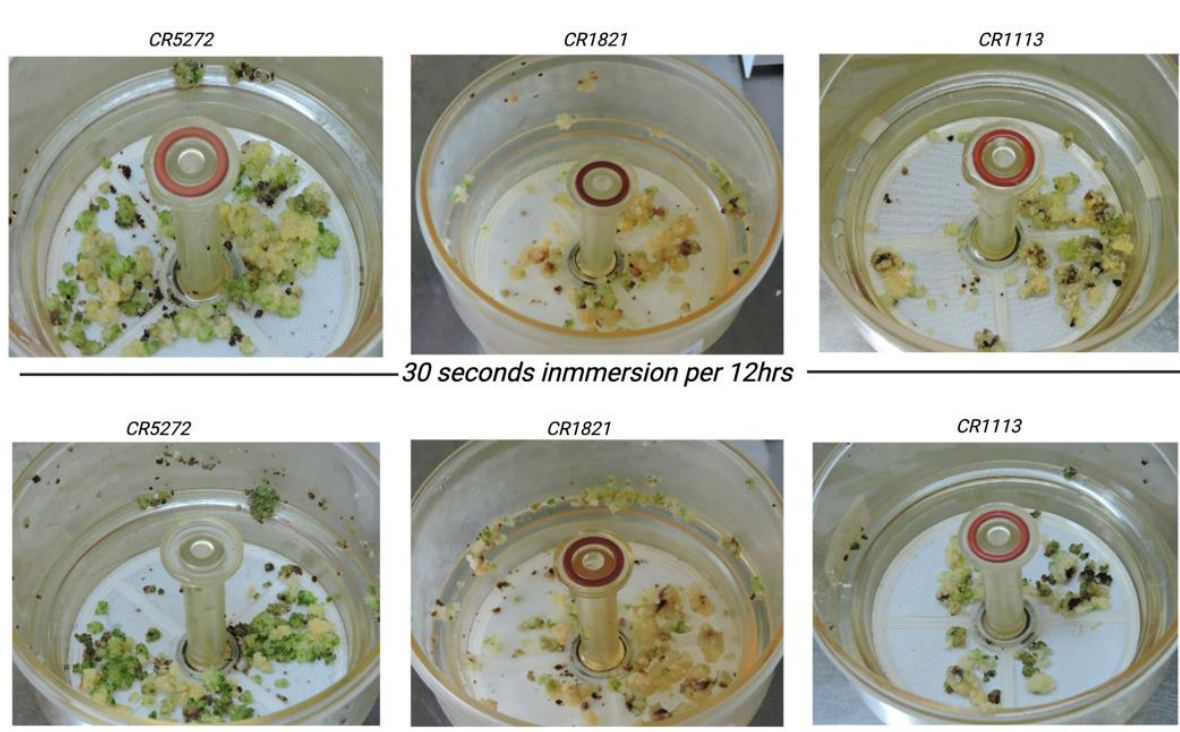

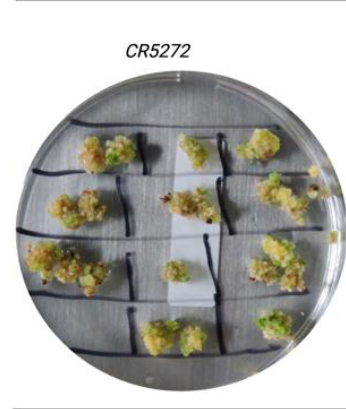

(A.)
60 seconds inmmersion per $12 \mathrm{hrs}$

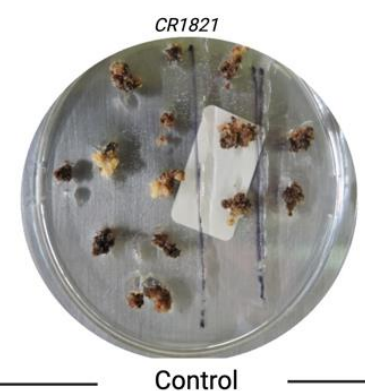

(B.)

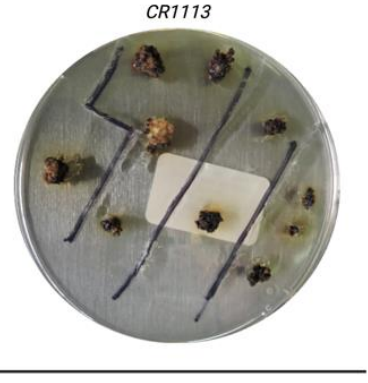

(C.)

Figure 5. Regeneration of cultivars CR5272 and recalcitrant CR1821 and CR1113 in MS medium with $0.5 \mathrm{mg}$ ANA $+3 \mathrm{mg}$ BAP from calli induced with $2 \mathrm{mg} / \mathrm{L}$ of 2,4-D. (A) CR5272 regeneration in SIT with immersion for 30 seconds per 12 hours, immersion for 60 seconds per 12 hours and the semisolid medium control; (B) CR1821 regeneration in SIT with immersion for 30 seconds per 12 hours, immersion for 60 seconds per 12 hours and the semisolid medium control; (C) CR1113 regeneration in SIT with immersion for 30 seconds per 12 hours, immersion for 60 seconds per 12 hours and the semisolid medium control. The absence of regeneration of the recalcitrant cultivars CR1821 and CR1113 was observed in the semisolid media.

\section{Discussion}

The present work optimized in vitro gamma ray (60Co) mutagenesis in an embryogenic callus of a recalcitrant Costa Rican cultivar. The cultivar seems to be related to Southeast Asian rice cultivars based on its Rubisco sequence pattern. The best callus induction was observed on MS with 2,4-D and regeneration with MS with $0.5 \mathrm{mg}$ ANA + $3 \mathrm{mg}$ BAP. This result is similar to that obtained by other authors on Southeast Asian cultivars such as Malaysia MR219, where 2,4-D is critical and performs the best as an inducer at 2 $\mathrm{mg} / \mathrm{L}^{20,21}$. Regeneration was improved using a temporal immersion system (RITA®) with either 60 or 120 seconds of immersion every 8 hours, which achieved a predictable and more homogeneous regeneration response. The radiation dose at which to start mutagenesis was proposed as a lethal dose 20 at $60 \mathrm{~Gy}$, as regeneration was not affected but remained as high as $80 \%$. At $80 \mathrm{~Gy}$, the regeneration fell to $30 \%$, consistent with the oxidative damage provoked by radiation and corresponding to the lethal dose 30 of the embryogenic calli. We believe $60 \mathrm{~Gy}$ is an excellent condition to start mutagenesis, considering 
that in other in vitro plants, such as pineapple, potato, and banana, a 5-40 Gy dose of gamma irradiation was shown to be sufficient to produce variability ${ }^{24}$. The calculated radiation dose of the cultivar at $60 \mathrm{~Gy}$ was the same as the LD50 for CR5272 ${ }^{13}$.

Optimization of embryogenic calli of a recalcitrant cultivar is essential for the following reasons. First, the alternative immersion method allowed our material to fully generate homogeneous and predictable in vitro plants after irradiation and was demonstrated to work for our cultivar and other recalcitrant rice lines. An immersion system is a littleexplored tool for gamma radiation mutagenesis with great potential. The constant liquid and airflow can dilute oxidation compounds and facilitate more homogeneous exposure to nutrients. We validated the results with recalcitrant cultivars CR1821 and CR1113, which showed regeneration rates above $40 \%$, which contrasted with null regeneration in the conventional semisolid method. Second, we can develop desired mutations in a cultivar that farmers are already using, which consequently leads to faster breeding and adoption of a derived improved cultivar. Rice traits associated with specific genes are well known, which paves the way for producing novel cultivars based on mutation of desired or required conditions, such as biotic and abiotic stress tolerance ${ }^{10}$.

Plant cultivars' nonhomogeneous in vitro behavior is not fully understood, but recent discoveries provide insights into the genetic basis of sucrose metabolism and oxidation. External phytohormones seem to trigger rice sucrose metabolism required for regeneration. The system appears to rely on the expression of endogenous cytokinin, auxin, and ABA signaling genes: ORR1, PIN-formed 1, and late embryogenesis-abundant $1^{26}$. The expression of OsSRO1c, a regulator of oxidative stress, seems to be vital for avoiding callus browning in indica cultivars 27 .

Tissue culture and gamma radiation produce oxidation via reactive oxygen species (ROS), which are usually contained in chloroplasts, peroxisomes, and mitochondria. ROS include superoxide $\mathrm{O}_{2}$, hydroxyl $\mathrm{OH}$ radicals, $\mathrm{H}_{2} \mathrm{O}_{2}$ and $\mathrm{HO}_{2}$. Tissue culture and gamma rays trigger ROS, consequently damaging the DNA by oxidation of the molecule into 8oxo-7-hydroxyguanosine (8-oxo-dG) and further transversions of $\mathrm{C} / \mathrm{G}$ and $\mathrm{T} / \mathrm{A}^{25}$. SIT seems to help overcome oxidation while allowing the tissue to recover.

\section{Materials and Methods}

\subsection{Embryogenic callus production}

For initial assays, the palea and lemma of rice caryopsis of a commercial indica cultivar were removed with No. 80 grit sandpaper. The obtained seeds were surface-sterilized as previously reported ${ }^{13}$ through two incubations in $4 \%(\mathrm{v} / \mathrm{v}) \mathrm{NaOCl}$ for 10 min each with constant agitation, using $10 \mathrm{~mL}$ of disinfectant solution for every gram of seeds. After the first and final incubation, the seeds were washed six to seven times with distilled sterilized water and were cultured in media composed of mineral salts and vitamins as described by Murashige and Skoog (MS, 1962), with $20 \mathrm{~g}$. L-1 sucrose and $0.1 \mathrm{~g}$. L-1 hydrolyzed casein. Treatments consisted of supplementing the basal medium with one of the following combinations of plant growth regulators: $2.5 \mathrm{mg}$. L-1 2,4-dichlorophenoxyacetic acid (2,4-D) was used as a control, a second treatment with a lowered concentration of $2.0 \mathrm{mg}$. $\mathrm{L}^{-1} 2,4^{-}$ $\mathrm{D}$, a third treatment consisting of $1.0 \mathrm{mg}$. $\mathrm{L}^{-1}$ 2,4-D $+1 \mathrm{mg}$. L-1 6-benzylaminopurine (6$\mathrm{BAP})$, a fourth treatment consisting of $2.0 \mathrm{mg}$. $\mathrm{L}^{-1} 2,4-\mathrm{D}+1 \mathrm{mg}$. L-1 $6-\mathrm{BAP}$, and a fifth treatment consisting of $2.0 \mathrm{mg}$. $\mathrm{L}^{-1}$ 2,4-D + 0,25 mg. L-1 1-phenyl-3-(1,2,3-thidiazol-5-yl)urea (thidiazuron, TDZ). After adding plant growth regulators, the media volumes were adjusted as required, the $\mathrm{pH}$ was adjusted to 5.8 with $1 \mathrm{~N} \mathrm{NaOH}$ or $1 \mathrm{~N} \mathrm{HCl}$, and $5.4 \mathrm{~g}^{\text {. L }}{ }^{-1}$ Gelzan $\AA^{\circledR}$ was added as a gelling agent. All previously mentioned chemicals were supplied by Phytotechnology Laboratories ${ }^{\circledR}$ (Shawnee Mission, Kansas, USA). After sterilization in an autoclave (1.2 ATM.cm ${ }^{-2}$ and $\left.121^{\circ} \mathrm{C}\right)$ for $30 \mathrm{~min}, 20 \mathrm{~mL}$ of medium was dispensed on $94 \times 16 \mathrm{~mm}$ vented polystyrene Petri dishes (Greiner Bio-One, Fisher-Scientific, Waltham, Massachusetts, USA) in a laminar flow chamber. For each treatment, at least 900 seeds were cultured after surface sterilization. Light parameters for all treatments were an intensity of $72 \mu \mathrm{mol} \cdot \mathrm{s}-1 \cdot \mathrm{m}-2$, a photoperiod of $16 \mathrm{~h}$ and a temperature of $26 \pm 2$ ${ }^{\circ} \mathrm{C}$. Regeneration, sprouting, and oxidation were recorded as response variables and 
analyzed in a completely randomized design with a generalized linear model with a Poisson distribution and logit link function. Post hoc analysis consisted of a Honest Significant Difference test to establish differences between the means.

4.2. Molecular markers

A NucleoSpinTM Tissue Kit from Macherey-Nagel (Germany) was used for DNA extraction, and Thermo Fisher K1071 was used for the subsequent PCR following the recommendations of the manufacturer. The primers used in this study are described as follows: for Rubisco, rbcLaf 5'ATGTCACCACAAACAGAGACTAAAGC3' and rbcLar 5'GTAAAATCAAGTCCACCRCG-3' or rbcLaf 5'ATGTCACCACAAACAGAGACTAAAGC3' and rbcLr590 5'AGTCCACCGCGTAGACATTCAT-3'; for MatK, matkxf 5'TAATTTACGATCAATTCATTC-3' and matkr 5'ACAAGAAAGTCGAAGTAT-3'. The thermocycling program was $95^{\circ} \mathrm{C}$ for 5 minutes, 40 cycles at $95^{\circ} \mathrm{C}$ for $45 \mathrm{~s}, 55^{\circ} \mathrm{C}$ for $45 \mathrm{~s}$ and $72{ }^{\circ} \mathrm{C}$ for $1 \mathrm{~min}$, and a final cycle of $72{ }^{\circ} \mathrm{C}$ for 7 minutes.

\subsection{Gamma Radiation}

Embryogenic callus radiation was achieved with a $\mathrm{CoS} 44 \mathrm{HH}-\mathrm{N}$ Ob-Servo Ignis with 24 cobalt 60 sources (Institute of Isotopes Co, Ltd., Budapest, Hungary) with gradient exposure from 0 to $120 \mathrm{~Gy}$, ten repetitions, and 20 embryogenic calli per exposure. IBM SPSS version 27 was used to calculate the lethal dose for the statistical probit analysis.

\section{Conclusions}

This section is not mandatory but can be added to the manuscript if the discussion is unusually long or complex.

\section{Patents}

NA.

Supplementary Materials:

Table S1. Lethal doses based on the probit model

\begin{tabular}{|c|c|c|c|}
\hline \multirow{2}{*}{ Probability } & \multirow[t]{2}{*}{ Estimate } & \multicolumn{2}{|c|}{ 95\% Confidence limits for Doses } \\
\hline & & Lower Limit & Upper Limit \\
\hline 0,01 & $-15,03$ & $-28,403$ & $-4,387$ \\
\hline 0,02 & $-0,373$ & $-11,855$ & 8,821 \\
\hline 0,03 & 8,926 & $-1,383$ & 17,23 \\
\hline 0,04 & 15,922 & 6,474 & 23,575 \\
\hline 0,05 & 21,612 & 12,848 & 28,754 \\
\hline 0,06 & 26,455 & 18,259 & 33,176 \\
\hline 0,07 & 30,702 & 22,989 & 37,068 \\
\hline 0,08 & 34,504 & 27,212 & 40.565 \\
\hline 0,09 & 37,962 & 31,04 & 43,757 \\
\hline 0,1 & 41,145 & 34,552 & 46,708 \\
\hline 0,15 & 54,325 & 48,927 & 59,09 \\
\hline 0,2 & 64,799 & 60,083 & 69,2 \\
\hline 0,25 & 73,785 & 69,388 & 78,139 \\
\hline 0,3 & 81,855 & 77,507 & 86,403 \\
\hline 0,35 & 89,333 & 84,838 & 94,254 \\
\hline
\end{tabular}




\begin{tabular}{llll}
0,4 & 96,429 & 91,649 & 101,85 \\
0,45 & 103,29 & 98,132 & 109,305 \\
0.5 & 110,05 & 104,44 & 116,72 \\
0.55 & 116,81 & 110,68 & 124,193 \\
0,6 & 123,67 & 116,98 & 131,831 \\
0,65 & 130,77 & 123,46 & 139,761 \\
0,7 & 138,25 & 130,25 & 148,148 \\
0,75 & 146,32 & 137,56 & 157,225 \\
0,8 & 155,3 & 145,67 & 167,356 \\
0,85 & 165,78 & 155,1 & 179,188 \\
0,9 & 178,96 & 166,95 & 194,101 \\
0,91 & 182,14 & 169,81 & 197,706 \\
0,92 & 185,6 & 172,91 & 201,624 \\
0,93 & 189,4 & 176,32 & 205,934 \\
0,94 & 193,65 & 180,13 & 210,748 \\
0,95 & 198,49 & 184,47 & 216,241 \\
0,96 & 204,18 & 189,56 & 222,696 \\
0,97 & 211,18 & 195,83 & 230,635 \\
0,98 & 220,47 & 204,15 & 241,193 \\
0,99 & 235,13 & 217,26 & 257,841 \\
\hline
\end{tabular}

Author Contributions: Conceptualization, A.H.-S., J.P.-C., R.F.-Z, R.R.-V, and A.G.-A; writingoriginal draft preparation, A.H.-S, J.P.-C., and A.G.-A.; writing-review and editing, A.H.-S, J.P.-C., A.G.-A, and A.A.-E; visualization, A.H.-S and J.P.-C. All authors have read and agreed to the published version of the manuscript.

Funding: This research was funded by the Research Vice-Rectory of TEC, Costa Rica, project number 1510-1022.

Data Availability Statement: In this section, please provide details regarding where data supporting the reported results can be found, including links to publicly archived datasets analyzed or generated during the study. Please refer to the suggested Data Availability Statements in the section "MDPI Research Data Policies" at https://www.mdpi.com/ethics. You might choose to exclude this statement if the study did not report any data.

Acknowledgments: In this section, you can acknowledge any support given which is not covered by the author contribution or funding sections. This may include administrative and technical support or donations in kind (e.g., materials used for experiments).

Conflicts of Interest: “The authors declare no conflicts of interest.”

\section{References}

(1) Wing, R. A.; Purugganan, M. D.; Zhang, Q. The Rice Genome Revolution: From an Ancient Grain to Green Super Rice. Nature Reviews Genetics 2018, 19 (8), 505-517. https://doi.org/10.1038/s41576018-0024-z.

(2) Chen, E.; Huang, X.; Tian, Z.; Wing, R. A.; Han, B. The Genomics of Oryza Species Provides Insights into Rice Domestication and Heterosis. Annual Review of Plant Biology 2019, 70, 639-665. https://doi.org/10.1146/annurev-arplant-050718-100320. 
(3) Kim, K.; Lee, S. C.; Lee, J.; Yu, Y.; Yang, K.; Choi, B. S.; Koh, H. J.; Waminal, N. E.; Choi, H. il; Kim, N. H.; Jang, W.; Park, H. S.; Lee, J.; Lee, H. O.; Joh, H. J.; Lee, H. J.; Park, J. Y.; Perumal, S.; Jayakodi, M.; Lee, Y. S.; Kim, B.; Copetti, D.; Kim, S.; Kim, S.; Lim, K. B.; Kim, Y. D.; Lee, J.; Cho, K. S.; Park, B. S.; Wing, R. A.; Yang, T. J. Complete Chloroplast and Ribosomal Sequences for 30 Accessions Elucidate Evolution of Oryza AA Genome Species. Scientific Reports 2015, 5 (September), 1-13. https://doi.org/10.1038/srep15655.

(4) Nadir, S.; Xiong, H. B.; Zhu, Q.; Zhang, X. L.; Xu, H. Y.; Li, J.; Dongchen, W.; Henry, D.; Guo, X. Q.; Khan, S.; Suh, H. S.; Lee, D. S.; Chen, L. J. Weedy Rice in Sustainable Rice Production. A Review. Agronomy for Sustainable Development 2017, 37 (5). https://doi.org/10.1007/s13593-0170456-4.

(5) Chauhan, B. S.; Jabran, K.; Mahajan, G. Rice Production Worldwide; 2017. https://doi.org/10.1007/978-3-319-47516-5.

(6) Viana, V. E.; Pegoraro, C.; Busanello, C.; Costa de Oliveira, A. Mutagenesis in Rice: The Basis for Breeding a New Super Plant. Frontiers in Plant Science 2019, 10 (1326), 1-28. https://doi.org/10.3389/fpls.2019.01326.

(7) Serrat, X.; Esteban, R.; Guibourt, N.; Moysset, L.; Nogués, S.; Lalanne, E. EMS Mutagenesis in Mature Seed-Derived Rice Calli as a New Method for Rapidly Obtaining TILLING Mutant Populations. Plant Methods 2014, 10 (1). https://doi.org/10.1186/1746-4811-10-5.

(8) Soriano, J. D. Mutagenic Effects of Gamma Radiation on Rice. Botanical Gazette 1961, 123 (1), 57 63.

(9) Romero, F. M.; Gatica-Arias, A. CRISPR/Cas9: Development and Application in Rice Breeding. Rice Science 2019, 26 (5), 265-281. https://doi.org/10.1016/j.rsci.2019.08.001.

(10) Hernández-Soto, A.; Echeverría-Beirute, F.; Abdelnour-Esquivel, A.; Valdez-Melara, M.; Boch, J.; Gatica-Arias, A. Rice Breeding in the New Era: Comparison of Useful Agronomic Traits. Current Plant Biology 2021, 27, 100211. https://doi.org/10.1016/j.cpb.2021.100211.

(11) Oladosu, Y.; Rafii, M. Y.; Abdullah, N.; Hussin, G.; Ramli, A.; Rahim, H. A.; Miah, G.; Usman, M. Principle and Application of Plant Mutagenesis in Crop Improvement: A Review. Biotechnology and Biotechnological Equipment 2016, 30 (1), 1-16. https://doi.org/10.1080/13102818.2015.1087333.

(12) Zain, C. R. C. M.; Kadhimi, A. A.; Alhasnawi, A. N.; Isahak, A.; Mohamad, A.; Doni, F.; Yusoff, W. M. W. Enhancing of Drought-Tolerant Rice (Oryza Sativa) Variety MRQ74 through Gamma Radiation and in Vitro Pathway. Biotechnology 2016, 15 (6), 125-134. https://doi.org/10.3923/biotech.2016.125.134.

(13) Abdelnour-Esquivel, A.; Perez, J.; Rojas, M.; Vargas, W.; Gatica-Arias, A. Use of Gamma Radiation to Induce Mutations in Rice (Oryza Sativa L.) and the Selection of Lines with Tolerance to Salinity and Drought. In Vitro Cellular and Developmental Biology - Plant 2020, 56 (1), 88-97. https://doi.org/10.1007/s11627-019-10015-5.

(14) Fehér, A. Callus, Dedifferentiation, Totipotency, Somatic Embryogenesis: What These Terms Mean in the Era of Molecular Plant Biology? Frontiers in Plant Science 2019, 10 (536). https://doi.org/10.3389/fpls.2019.00536.

(15) Rima, K.; Pankaj, K.; Sharma, V. K.; Harsh, K. Effect of Culture Media on Seed Germination and Callus Induction from Cultured Seeds of Rice Cultivars. 2020, No. February.

(16) Vega, R.; Vásquez, N.; Espinoza, A. M.; Gatica, A. M.; Valdez-Melara, M. Histology of Somatic Embryogenesis in Rice (Oryza Sativa Cv. 5272). Revista de Biologia Tropical 2009, 57 (SUPPL. 1), 141-150. https://doi.org/10.15517/rbt.v57i0.21291. 
(17) Radziah C.M.Z., C.; Naji Alhasnawi, A.; A. Kadhimi, A.; Isahak, A.; Mohamad, A.; Farshad Ashraf, M.; Doni, F.; Mohtar Wan Yusoff, W. Development of a Technique for Callus Induction and Plant Regeneration in <em>Oryza Sativa</Em> L. Var. MRQ74 and MR269. Advance Journal of Food Science and Technology 2017, 13 (3), 128-137. https://doi.org/10.19026/ajfst.13.4149.

(18) Murashige, T.; Skoog, F. A Revised Medium for Rapid Growth and Bio Assays with Tobacco Tissue Cultures. Physiologia Plantarum 1962, 15 (3), 474-497. https://doi.org/10.1111/j.13993054.1962.tb08052.x.

(19) Valdez, M.; Muñoz, M.; Vega, J. R.; Espinoza, A. M. Plant Regeneration of Indica Rice (Oryza Sativa) Cultivars from Mature Embryo-Derived Calli. Revista de biología tropical 1997, 44-45 (3), 1321. https://doi.org/10.15517/rbt.v44i3.21827.

(20) Pawar, B.; Kale, P.; Bahurupe, J.; Jadhav, A.; Kale, A.; Pawar, S. Proline and Glutamine Improve in Vitro Callus Induction and Subsequent Shooting in Rice. Rice Science 2015, 22 (6), 283-289. https://doi.org/10.1016/j.rsci.2015.11.001.

(21) Abiri, R.; Maziah, M.; Shaharuddin, N. A.; Yusof, Z. N. B.; Atabaki, N.; Hanafi, M. M.; Sahebi, M.; Azizi, P.; Kalhori, N.; Valdiani, A. Enhancing Somatic Embryogenesis of Malaysian Rice Cultivar MR219 Using Adjuvant Materials in a High-Efficiency Protocol. International Journal of Environmental Science and Technology 2017, 14 (5), 1091-1108. https://doi.org/10.1007/s13762-016-1221-y.

(22) Hussain, Z.; Khan, M. H.; Bano, R.; Rashid, H.; Chaudhry, Z. Protocol Optimization for Efficient Callus Induction and Regeneration in Three Pakistani Rice Cultivars. Pakistan Journal of Botany 2010, 42 (2), 879-887.

(23) Ming, N. J.; Mostafiz, S. B.; Johon, N. S.; Zulkifli, N. S. A.; Wagiran, A. Combination of Plant Growth Regulators, Maltose, and Partial Desiccation Treatment Enhance Somatic Embryogenesis in Selected Malaysian Rice Cultivar. Plants 2019, 8 (6). https://doi.org/10.3390/plants8060144.

(24) Kashtwari, M.; Mansoor, S.; Wani, A. A.; Najar, M. A.; Deshmukh, R. K.; Baloch, F. S.; Abidi, I.; Zargar, S. M. Random Mutagenesis in Vegetatively Propagated Crops: Opportunities, Challenges and Genome Editing Prospects. Molecular Biology Reports 2021. https://doi.org/10.1007/s11033-02106650-0.

(25) Xie, X.; He, Z.; Chen, N.; Tang, Z.; Wang, Q.; Cai, Y. The Roles of Environmental Factors in Regulation of Oxidative Stress in Plant. BioMed Research International 2019, 2019, 21-27. https://doi.org/10.1155/2019/9732325.

(26) Lee, S. T.; Huang, W. L. Cytokinin, Auxin, and Abscisic Acid Affects Sucrose Metabolism Conduce to de Novo Shoot Organogenesis in Rice (Oryza Sativa L.) Callus. Botanical Studies 2013, 54 (1), 1 11. https://doi.org/10.1186/1999-3110-54-5.

(27) Zhang, K.; Su, J.; Xu, M.; Zhou, Z.; Zhu, X.; Ma, X.; Hou, J.; Tan, L.; Zhu, Z.; Cai, H.; Liu, F.; Sun, H.; Gu, P.; Li, C.; Liang, Y.; Zhao, W.; Sun, C.; Fu, Y. A Common Wild Rice-Derived BOC1 Allele Reduces Callus Browning in Indica Rice Transformation. Nature Communications 2020, 11 (1). https://doi.org/10.1038/s41467-019-14265-0. 